\title{
A EFETIVAÇÃO DOS DIREITOS SOCIAIS COMO INSTRUMENTO PARA O DESENVOLVIMENTO NA CONSTITUIÇÃO BRASILEIRA
}

\author{
EFFECTIVENESS OF SOCIAL RIGHTS AS AN INSTRUMENT FOR DEVELOPMENT IN \\ THE BRAZILIAN CONSTITUTION
}

Pedro Abib Hecktheuer ${ }^{1}$

Bruna Borges Moreira Lourenço²

\begin{abstract}
RESUMO
O objetivo da pesquisa é compreender se a Constituição Federal de 1988 estabelece o desenvolvimento como um direito fundamental a ser concretizado por meio da implementação dos direitos sociais por ela previstos. Com a pesquisa foi possível demonstrar a relevância dada ao direito ao desenvolvimento na Constituição da República Federativa do Brasil de 1988, alçando-o à direito fundamental, compreendido muito para além de uma perspectiva meramente econômica. Portanto, foi possível demonstrar que a promoção de direitos sociais e a vedação do retrocesso neste tipo de direitos é uma condição para o atingimento do desenvolvimento. Para alcançar os resultados da pesquisa foi necessário utilizar-se de uma pesquisa bibliográfica e das normas constitucionais, sendo que na fase de tratamento de dados usou-se o método cartesiano.
\end{abstract}

PALAVRAS-CHAVE: Desenvolvimento; Direito Fundamental; Direitos Sociais; Retrocesso.

\section{ABSTRACT}

The objective of the research is to understand if the Federal Constitution of 1988 establishes the development as a fundamental right to be realized through the implementation of the social rights provided for by it. With the research it was possible to demonstrate the relevance given to the right to development in the Constitution of the Federative Republic of Brazil of 1988, raising it to a fundamental

1 Doutorando em Direito pela Universidad de Alicante (UA). Mestre em Direito Econômico e Socioambiental pela Pontifícia Universidade Católica do Paraná (PUCPR). Bolsista junto à Fundação de Amparo ao Desenvolvimento das Ações científicas e tecnológicas e à Pesquisa do Estado de Rondônia (FAPERO/CAPES). Professor de Direito Constitucional da Faculdade Católica de Rondônia e Coordenador do Curso de Direito da Faculdade Católica de Rondônia (FCR). Coordenador do Grupo de Pesquisa "Direitos Fundamentais e Políticas Públicas", cadastrado no DGP do CNPq. Advogado. E-mail: pedro@fcr.edu.br.

2 Doutoranda em Direito pela Univerisdad de Alicante (UA). Mestre em Ciência Jurídica pela Universidade do Vale do Itajaí (UNIVALI) e em Derecho Ambiental y de la Sostenibilidad pela Universidad de Alicante (UA). Advogada. Florianópolis, Santa Catarina. Brasil E-mail: bruna.bml@hotmail.com. 
HECKTHEUER, Pedro Abib; LOURENÇO, Bruna Borges Moreira. A efetivação dos direitos sociais como instrumento para o desenvolvimento na Constituição brasileira. Revista Eletrônica Direito e Política, Programa de Pós-Graduação Stricto Sensu em Ciência Jurídica da UNIVALI, Itajaí, v.14, n.2, 20 quadrimestre de 2019. Disponível em: www.univali.br/direitoepolitica - ISSN 1980-7791

right level, understood far beyond a purely economic perspective. Therefore, it was possible to demonstrate that the promotion of social rights and the sealing of social rights regression are a condition for achieving development. To reach the results of the research it was necessary to use a bibliographic research and the constitutional norms, and in the data treatment phase the Cartesian method was used.

KEYWORDS: Development; Fundamental Right; Social Rights.

\section{INTRODUÇÃO}

A compreensão sobre o fenômeno Desenvolvimento exige uma superação das concepções ideológicas ou mesmo associadas apenas ao simples crescimento econômico. A análise do desenvolvimento que aqui se está a trabalhar partem, especialmente, do um autor que suscitou essa mudança paradigmática sobre o fenômeno, qual seja, Amartya Sen, especialmente com sua obra Desenvolvimento como Liberdade. Sob essa perspectiva de desenvolvimento, possibilitou-se o aprofundamento do fenômeno e sua compreensão a partir das preceituações constitucionais, no Brasil.

Quando o desenvolvimento ganha contornos diferentes daquela compreensão de meados da última década do século passado - que o associava amplamente ao crescimento econômico - passou-se a englobar uma série de liberdades essenciais ao pleno desenvolvimento, em especial àquelas que passaram a ser positivadas nos ordenamentos constitucionais particulares na forma de direitos fundamentais sociais.

Nesse sentido, a indagação central da pesquisa é se o desenvolvimento é compreendido como um direito fundamental na Constituição Brasileira de 1988 e se os direitos fundamentais sociais são mecanismos essenciais para a sua concretização. Portanto, em sendo assim compreendido, é necessário analisar se o retrocesso deste tipo de direitos impediria o pleno de desenvolvimento humano no Brasil.

A hipótese é que a Constituição Federal de 1988 prevê o desenvolvimento como um direito fundamental e que, para a sua concretização, exigem-se, dentre outras ações, que sejam eliminadas as privações de liberdades existentes no país, por 
HECKTHEUER, Pedro Abib; LOURENÇO, Bruna Borges Moreira. A efetivação dos direitos sociais como instrumento para o desenvolvimento na Constituição brasileira. Revista Eletrônica Direito e Política, Programa de Pós-Graduação Stricto Sensu em Ciência Jurídica da UNIVALI, Itajaí, v.14, n.2, $2^{\circ}$ quadrimestre de 2019. Disponível em: www.univali.br/direitoepolitica - ISSN 1980-7791

meio da promoção de direitos sociais. Além disso, acredita-se que qualquer retrocesso no que diz respeito a implementação deste tipo de direitos incide em um obstáculo ao desenvolvimento no país.

A pesquisa conducente à redação do presente relatório teve como objetivo geral compreender se a Constituição Federal de 1988 estabelece o desenvolvimento como um direito fundamental a ser concretizado por meio da implementação dos direitos sociais por ela previstos. Ainda objetivou-se analisar se o retrocesso em termos de promoção dos direitos sociais não seria um obstáculo ao desenvolvimento no país.

Para o desenvolvimento de uma pesquisa, um dos elementos essenciais refere-se à relação entre os objetivos da investigação e os procedimentos metodológicos utilizados para alcançá-los, ou seja, de que forma esses objetivos foram alcançados.

Para a presente pesquisa utilizou-se como caminho o estudo bibliográfico, sem deixar de se apegar ao objeto de estudo da ciência jurídica, qual seja, a norma jurídica, neste caso a Constituição Federal. Foi necessário, pois, uma revisão teórica sobre as categorias Desenvolvimento, Direitos Fundamentais e Sociais e Retrocesso Social.

Quanto à Metodologia empregada, registra-se que na fase de investigação ${ }^{3}$ foi utilizado o Método Indutivo ${ }^{4}$, na fase de tratamento de dados o método cartesiano 5 e, o relatório dos resultados expresso no presente artigo é composto na base lógica indutiva.

Com esses procedimentos foi possível responder ao problema e alcançar os objetivos da pesquisa, organizando-se o artigo em dois capítulos, da seguinte

\footnotetext{
3 "[...] momento no qual o Pesquisador busca e recolhe os dados, sob a moldura do Referente estabelecido[...]. PASOLD, Cesar Luiz. Prática da Pesquisa jurídica e Metodologia da pesquisa jurídica. 10 ed. Florianópolis: OAB-SC editora, 2007. p. 101.

4 "[...] pesquisar e identificar as partes de um fenômeno e colecioná-las de modo a ter uma percepção ou conclusão geral [...]". PASOLD, Cesar Luiz. Prática da Pesquisa jurídica e Metodologia da pesquisa jurídica. p. 104.

${ }^{5}$ Sobre as quatro regras do Método Cartesiano (evidência, dividir, ordenar e avaliar) veja LEITE, Eduardo de oliveira. A monografia jurídica. 5 ed. São Paulo: Revista dos Tribunais, 2001. p. 2226.
} 
HECKTHEUER, Pedro Abib; LOURENÇO, Bruna Borges Moreira. A efetivação dos direitos sociais como instrumento para o desenvolvimento na Constituição brasileira. Revista Eletrônica Direito e Política, Programa de Pós-Graduação Stricto Sensu em Ciência Jurídica da UNIVALI, Itajaí, v.14, n.2, $2^{\circ}$ quadrimestre de 2019. Disponível em: www.univali.br/direitoepolitica - ISSN 1980-7791

maneira: (1) A relevância do direito ao desenvolvimento na Constituição da República Federativa do Brasil; e (2) A essencialidade dos direitos sociais e a proibição do retrocesso como uma condição ao desenvolvimento.

\section{A RELEVÂNCIA DO DIREITO AO DESENVOLVIMENTO NA CONSTITUIÇÃO DA REPÚBLICA FEDERATIVA DO BRASIL}

O desenvolvimento para o âmbito jurídico passou a ser pauta muito recentemente. No Brasil, a discussão é inaugurada, em termos constitucionais, de maneira bastante tímida, na Constituição de 1967 e na Emenda Constitucional de 1969, momentos em que a compreensão dada ao desenvolvimento ainda era bastante restrita à ideia de crescimento econômico ${ }^{6}$.

Foi mesmo a partir da Constituição Federal de 1988 que o tratamento ao Desenvolvimento passou a ser aprofundado e ampliado, tornando o conceito interdisciplinar e não mais restrito à questão econômica. Isso se deu em função das discussões teóricas nas principais academias nesse período, o que também levou a Organização das Nações Unidas (ONU) a abandonar o Produto Interno Bruto como índice para a mensuração do desenvolvimento dos países, em 19907.

Essa mudança na compreensão de desenvolvimento para os juristas brasileiros fica latente quando, nas notas preambulares da Constituição Federal de 1988, anuncia-se que a Assembleia Constituinte instituiu "um Estado Democrático, destinado a assegurar (...) o desenvolvimento". Deve-se ressaltar que não houve nenhuma menção a econômico, ou seja, não se restringiu o alcance ao termo, afastando-se daquela visão puramente econômica.

A importância dada ao desenvolvimento, lato senso, e o afastamento do caráter meramente econômico dado pela Constituição fica evidente quando se faz a leitura

\footnotetext{
${ }^{6}$ FOLLONI, André. A complexidade ideológica, jurídica e política do desenvolvimento sustentável e a necessidade de compreensão interdisciplinar do problema. Revista de Direitos Humanos Fundamentais, Osasco, jan-jun/2014, ano 14, n.1, pp. 71-72.

7 FOLLONI, André. A complexidade ideológica, jurídica e política do desenvolvimento sustentável e a necessidade de compreensão interdisciplinar do problema. Revista de Direitos Humanos Fundamentais, Osasco, jan-jun/2014, ano 14, n.1, pp. 72.
} 
HECKTHEUER, Pedro Abib; LOURENÇO, Bruna Borges Moreira. A efetivação dos direitos sociais como instrumento para o desenvolvimento na Constituição brasileira. Revista Eletrônica Direito e Política, Programa de Pós-Graduação Stricto Sensu em Ciência Jurídica da UNIVALI, Itajaí, v.14, n.2, 20 quadrimestre de 2019. Disponível em: www.univali.br/direitoepolitica - ISSN 1980-7791

dos objetivos da República Federativa do Brasil (Art. $\left.3^{0}\right)^{8}$, fazendo-se perceber que se alçou a um dos valores supremos da sociedade brasileira, com uma ampliação semântica e relevância normativa nunca antes vistas. O termo se repete em diversos outros dispositivos ao longo da Constituição Federal, seja em momentos que se aproxima da questão econômica, ou em outros afastando-a.

O termo desenvolvimento se repete por 53 vezes durante o texto da Constituição Federal, por diversos momentos associado diretamente à ideia de crescimento econômico ${ }^{9}$, em outros diversos se identifica não só em termos econômicos, mas também sociais ${ }^{10}$, em outros aprofunda e associa não só o econômico e social, mas também questões humanitárias e culturais ${ }^{11} \mathrm{e}$, ainda, há momentos em que o econômico é deixado à margem, sendo observados outros aspectos do desenvolvimento ${ }^{12}$.

Portanto, o que se pode observar é que o desenvolvimento já era um tema complexo, o que ainda persiste, pois as incertezas geradas pelas "rápidas mudanças de cenário político, econômico, tecnológico e social, somadas à dificuldade de consolidar tantos e tão diferentes campos de conhecimento, afetam (...) a compreensão do desenvolvimento"13.

Inclusive por isso, a sua compreensão em termos constitucionais é bastante complexa, pois o tema desenvolvimento é, como se viu, fundamental para a

8 BRASIL. Constituição da República Federativa do Brasil. Brasília: Senado Federal, 1988.

9 Exemplos de dispositivos que associam diretamente ao viés econômico: "desenvolvimento

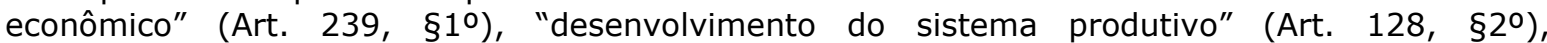
"desenvolvimento tecnológico e econômico" (Art. 50, XXIX), "desenvolvimento científico" (Art. 218, caput), "desenvolvimento científico e tecnológico" (art. 200, V), "desenvolvimento econômico e social (art. 21, IX), "desenvolvimento social e econômico" (art. 180)

10 Exemplos de dispositivos que associam aos vieses econômico e social: "desenvolvimento econômico e social" (art. 21, IX), "desenvolvimento social e econômico" (art. 180) e "desenvolvimento sócio-econômico" (Art. 151, I).

11 Exemplos de dispositivos que associam também a questões humanitárias e culturais: "desenvolvimento humano, social e econômico" (Art. 216-A) e "desenvolvimento cultural e sócioeconômico"(Art. 219).

12 Exemplos em que a questão econômica fica subjacente: "desenvolvimento da pessoa" (Art. 205; Art. 227, V), "desenvolvimento cultural" (Art. 215, §30), "desenvolvimento do ensino" (Art. 34, VII, e; Arts. 35, III; 167, IV; 212, caput; 214, caput), "desenvolvimento urbano" (Art. 21, XX e Art. 182, caput), "desenvolvimento nacional" (Art. 174, §1ํ), "desenvolvimento do país" (Art. 192, caput), e "desenvolvimento regional" (Art. 163, VII).

13 JÚNIOR, José Celso Cardoso; SIQUEIRA, Carlos Henrique Romão. Complexidade \& desenvolvimento: abordagem metodológica e panorama da discussão propagada pelo Ipea entre 2008 e 2010. Economia e Sociedade, v. 21, n. 4, p. 953. 
HECKTHEUER, Pedro Abib; LOURENÇO, Bruna Borges Moreira. A efetivação dos direitos sociais como instrumento para o desenvolvimento na Constituição brasileira. Revista Eletrônica Direito e Política, Programa de Pós-Graduação Stricto Sensu em Ciência Jurídica da UNIVALI, Itajaí, v.14, n.2, $2^{\circ}$ quadrimestre de 2019. Disponível em: www.univali.br/direitoepolitica - ISSN 1980-7791

Constituição Federal de 1988, tendo sido dada normatividade ao termo, exigindose, dessa forma, o seu aprofundamento.

Deve-se levar em consideração o contexto brasileiro no qual a Constituição está inserida, bem como os objetivos que o poder constituinte originário teve ao promulgar esta Constituição, que é carregada de intenções de transformação social, não mais com normas meramente programáticas, mas de aplicação imediata. Ou seja, a Constituição Federal retrata uma "avaliação da realidade socioeconômica e ambiental, juízos de valor (que) denotam avaliação negativa do que estava aí e, a partir dessa verificação avaliativa, constroem deveres de ação transformadora"14.

Um excelente exemplo de uma realidade a ser transformada está na questão das desigualdades no que diz respeito à riqueza, primeiro porque se fez uma avaliação negativa, constatando-se que o acúmulo de riqueza gerada é distribuído para poucos, já que é o Brasil um dos países mais desiguais do mundo ${ }^{15}$. Dessa forma, o Constituinte impôs, por meio dos objetivos (Art. 3), que a pobreza e a marginalização sejam "erradicadas" e que as desigualdades sejam "diminuídas" (art. $\left.3^{\circ}, \mathrm{III}\right)^{16}$.

Nesse aspecto, não se pode deixar de considerar que a Constituição está se preocupando com o aspecto econômico do desenvolvimento, já que o viés econômico, como já visto, geralmente se liga ao processo de enriquecimento de pessoas e de países, ao aumento de riqueza material.

${ }^{14}$ FOLLONI, André. A complexidade ideológica, jurídica e política do desenvolvimento sustentável e a necessidade de compreensão interdisciplinar do problema. Revista de Direitos Humanos Fundamentais, Osasco, jan-jun/2014, ano 14, n.1, p. 74.

15 PIRES, Breiller. Brasil despenca 19 posições em ranking de desigualdade social da ONU. EI País, São Paulo, 21 de Março de 2017. Disponível em: https://brasil.elpais.com/brasil/2017/03/21/politica/1490112229 963711.html. Acessado em: 09/02/2018.

16 BRASIL. Constituição da República Federativa do Brasil. Brasília: Senado Federal, 1988. 
HECKTHEUER, Pedro Abib; LOURENÇO, Bruna Borges Moreira. A efetivação dos direitos sociais como instrumento para o desenvolvimento na Constituição brasileira. Revista Eletrônica Direito e Política, Programa de Pós-Graduação Stricto Sensu em Ciência Jurídica da UNIVALI, Itajaí, v.14, n.2, 20 quadrimestre de 2019. Disponível em: www.univali.br/direitoepolitica - ISSN 1980-7791

No entanto, não só se privilegia a produção, mas também é imposição constitucional a distribuição dessa riqueza, associado com a promoção de direitos sociais (Art. $\left.6^{0}\right)^{17}$, com o objetivo de promover a justiça sociall ${ }^{18}$ o bem-estar.

Quando a Constituição menciona o "desenvolvimento social", portanto, compreende-se a busca pelo desenvolvimento de toda a sociedade - e não apenas dos indivíduos -, bem como se entende a promoção dos direitos sociais ${ }^{19}$, sem que isso incorra em prejuízo ao "desenvolvimento econômico", pelo contrário.

Compreende-se, a partir do exemplo supracitado, que o desenvolvimento econômico é social, e vice-versa, no sentido de que há uma solidariedade entre ambos, não havendo desenvolvimento econômico separado do social, portanto, é isso que se depreende de uma interpretação sistemática da Constituição ${ }^{20}$ :

Enfim, o desenvolvimento, na Constituição de 1988, está ligado ao crescimento econômico, e negar essa ligação só é possível se se negligenciar a própria Constituição. Mas o desenvolvimento não se reduz a isso. É muito mais amplo e atinge todas as dimensões fundamentais do desenvolvimento humano em todas as suas potencialidades (...) 0 desenvolvimento constitucional liga-se, em uma bela formulação sintética, com o bem-estar ${ }^{21}$.

O desenvolvimento que permeia a Constituição de 1988 deve ser analisado sob um viés extrínseco - referente aos planos estatais, relacionado ao crescimento da produção econômica e ao equilíbrio da estruturação organizacional e financeira do Estado - e outro intrínseco - de caráter subjetivo, que se refere à implementação

17 BRASIL. Constituição da República Federativa do Brasil. Brasília: Senado Federal, 1988.

18 FOLLONI, André. A complexidade ideológica, jurídica e política do desenvolvimento sustentável e a necessidade de compreensão interdisciplinar do problema. Revista de Direitos Humanos Fundamentais, Osasco, jan-jun/2014, ano 14, n.1, pp. 79.

${ }^{19}$ Art. $6^{\circ}$ São direitos sociais a educação, a saúde, a alimentação, o trabalho, a moradia, o transporte, o lazer, a segurança, a previdência social, a proteção à maternidade e à infância, a assistência aos desamparados, na forma desta Constituição (BRASIL. Constituição da República Federativa do Brasil. Brasília: Senado Federal, 1988).

20 FOLLONI, André. A complexidade ideológica, jurídica e política do desenvolvimento sustentável e a necessidade de compreensão interdisciplinar do problema. Revista de Direitos Humanos Fundamentais, Osasco, jan-jun/2014, ano 14, n.1, pp. 77-78.

21 FOLLONI, André. A complexidade ideológica, jurídica e política do desenvolvimento sustentável e a necessidade de compreensão interdisciplinar do problema. Revista de Direitos Humanos Fundamentais, Osasco, jan-jun/2014, ano 14, n.1, pp. 80. 
HECKTHEUER, Pedro Abib; LOURENÇO, Bruna Borges Moreira. A efetivação dos direitos sociais como instrumento para o desenvolvimento na Constituição brasileira. Revista Eletrônica Direito e Política, Programa de Pós-Graduação Stricto Sensu em Ciência Jurídica da UNIVALI, Itajaí, v.14, n.2, $2^{\circ}$ quadrimestre de 2019. Disponível em: www.univali.br/direitoepolitica - ISSN 1980-7791

de condições materiais de existência digna que, somadas e inter-relacionadas, permitem aos cidadãos desenvolver plenamente sua personalidade ${ }^{22}$.

Pode-se dizer que a compreensão constitucional de desenvolvimento em muitos aspectos se aproxima da formulação teórica de Amartya Sen quando o iguala a ideia de liberdade. Um desenvolvimento que consiste na eliminação das privações de liberdade que limitam as escolhas e oportunidades de as pessoas exercerem a condição de agente ${ }^{23}$.

Para se aferir se as liberdades são suficientes a ponto de considerar um país desenvolvido, Amartya Sen apresentou as liberdades instrumentais ${ }^{24}$ como "ferramentas" que contribuirão para o aumento da liberdade humana em geral, ou seja, com a promoção de liberdades globais, que cabe relembrar, são elas: (1) as facilidades econômicas, (2) oportunidades sociais, (3) garantias de transparência e (4) segurança protetora e (5) liberdades políticas.

Eis que, em termos de intenções e imposições constitucionais, do que se discutiu até o momento, em muito se tem aproximado dessa compreensão de Amartya Sen, principalmente quando se discutiu que o desenvolvimento para a Constituição Federal contemplaria: (1) o desenvolvimento econômico; (2) o desenvolvimento social, no sentido de desenvolvimento da sociedade como um todo e da satisfação dos direitos sociais; (3) o desenvolvimento que contribua para o bem estar de todos, em equilíbrio; e (4) o desenvolvimento integral das potencialidades humanas e culturais.

Vê-se a grande ligação existente entre as "liberdades instrumentais" de Amartya Sen, quando comparadas com a compreensão extraída da Constituição Federal a respeito do desenvolvimento. Grande parte dessas liberdades instrumentais

22 FACHIN, Melina Girardi. Direito fundamental ao desenvolvimento: uma possível ressignificação entre a Constituição Brasileira e o Sistema Internacional de Proteção dos Direitos Humanos. PIOVESAN, Flávia; SOARES, Inês Virgínia Prado (Coords.). Direito ao desenvolvimento. Belo Horizonte: Fórum, p. 179-198, 2010, p. 180-193.

23 SEN, Amartya. Desenvolvimento como Liberdade. São Paulo: Companhia das Letras, 2000, p. 33.

24 SEN, Amartya. Desenvolvimento como Liberdade. São Paulo: Companhia das Letras, 2000, p. 58. 
HECKTHEUER, Pedro Abib; LOURENÇO, Bruna Borges Moreira. A efetivação dos direitos sociais como instrumento para o desenvolvimento na Constituição brasileira. Revista Eletrônica Direito e Política, Programa de Pós-Graduação Stricto Sensu em Ciência Jurídica da UNIVALI, Itajaí, v.14, n.2, 20 quadrimestre de 2019. Disponível em: www.univali.br/direitoepolitica - ISSN 1980-7791

referidas por Amartya Sen são trazidas em termos constitucionais como direitos, em especial os fundamentais/sociais.

Em verdade, a Constituição Federal ampliou sobremaneira essa concepção de desenvolvimento até aqui trabalhada, criando um novo paradigma, que contempla: (1) essa percepção da sustentabilidade social, para proporcionar as liberdades já elencadas e eliminar as suas privações, quais sejam, a busca pela redução da pobreza e das desigualdades sociais e a promoção de valores como justiça social e equidade; e (2) a promoção da sustentabilidade ambiental, ou seja, a sustentabilidade de espécies, ecossistemas e processos ecológicos ${ }^{25}$, com base em uma economia verde, que propugna um uso racional e solidário dos recursos naturais ${ }^{26}$.

A esse paradigma constitucional de desenvolvimento se denominou socioambientalismo, compreensão que procura dar manutenção aos bens (sócio)ambientais, sejam eles naturais ou culturais. São aqueles essenciais à manutenção da vida de todas as espécies (biodiversidade) e de todas as culturas humanas (sociodiversidade) ${ }^{27}$. Ele busca, portanto:

superar a dicotomia público/privado, qualifica as políticas públicas ambientais com os movimentos sociais, estabelece uma metodologia da ação social e ambiental, via um juízo crítico informado pelas políticas ambientais, promovendo uma pedagogia ambiental explicita, afirma o ambiente como 'um lugar de encontro', onde se dá a totalidade das relações, vale dizer um espaço físico apropriado para o exercício das ações socioambientais, promovendo um conjunto complexo de condições sociais, morais, naturais e culturais que cercam os seres vivos e neles podem influir decisivamente ${ }^{28}$.

25 SANTILLI, Juliana. Socioambientalismo e novos direitos: proteção jurídica à diversidade biológica e cultural. Editora Peirópolis LTDA, 2005, p. 34.

26 WOLKMER, Maria de Fátima Schumacher; DA SILVA PAULITSCH, Nicole. O Estado de Direito Socioambiental e a Governaça Ambiental: ponderações acerca da judicialização das políticas públicas ambientais e da atuação do poder judiciário. Novos Estudos Jurídicos, v. 18, n. 2, p. 256-268, 2013, p. 260.

27 MARÉS, Carlos Frederico. Introdução ao direito socioambiental. In: LIMA, André (Org.). O direito para o Brasil socioambiental. São Paulo: Instituto Socioambiental; Porto Alegre: Sérgio Antônio Fabris, 2002, p. 38.

28 MOLINARO, Carlos Alerto. Racionalidade ecológica e estado socioambiental e democrático de direito. 2006. 200 f. Dissertação (Mestrado em Direito) - Faculdade de Direito, Pontifícia Universidade Católica do Rio Grande do Sul, Porto Alegre, 2006. p. 144. 
HECKTHEUER, Pedro Abib; LOURENÇO, Bruna Borges Moreira. A efetivação dos direitos sociais como instrumento para o desenvolvimento na Constituição brasileira. Revista Eletrônica Direito e Política, Programa de Pós-Graduação Stricto Sensu em Ciência Jurídica da UNIVALI, Itajaí, v.14, n.2, 20 quadrimestre de 2019. Disponível em: www.univali.br/direitoepolitica - ISSN 1980-7791

Dessa forma, quando se debate o problema socioambiental, faz-se necessária a percepção multidimensional do fenômeno, "com base na observação do ser humano pertencente ao meio ambiente como um todo, numa relação indissociável de interdependência e transversalidade"29.

O fato é que esse paradigma da proteção socioambiental impõe "sob todos seus prismas um tratamento inovador, o que repercute também na perspectiva das políticas e das práticas do Estado"30 e, para fazer frente a esses desafios, estabelece-se a necessidade de um novo modelo de Estado, que contemple a tutela dos direitos sociais e ambientais em padrões sustentáveis, qual seja, o Estado de Direito Socioambiental ${ }^{31,32}$.

Um Estado que alça, no seu arcabouço jurídico constitucional, a proteção ambiental e social à condição de direito fundamental ${ }^{33}$, que, "longe de ser um Estado 'mínimo', é um Estado regulador da atividade econômica, capaz de dirigi-la e ajustá-la aos valores e princípios constitucionais, objetivando o desenvolvimento humano e social de forma ambientalmente sustentável". ${ }^{34}$

Não resta dúvidas que para a implementação e consecução desse Estado de Direito Socioambiental e, consequentemente, desse paradigma de desenvolvimento, fazse necessária a efetiva participação e engajamento da sociedade, que só

29 KALIL, Ana Paula Maciel Costa; FERREIRA, Heline Sivini. A dimensão socioambiental do Estado de Direito. Veredas do Direito: Direito Ambiental e Desenvolvimento Sustentável, v. 14, n. 28, p. 329-359, 2017, p. 333.

30 WOLKMER, Maria de Fátima Schumacher; DA SILVA PAULITSCH, Nicole. O Estado de Direito Socioambiental e a Governaça Ambiental: ponderações acerca da judicialização das políticas públicas ambientais e da atuação do poder judiciário. Novos Estudos Jurídicos, v. 18, n. 2, p. 256-268, 2013, p. 259.

31 SARLET, Ingo Wolfgang; FENSTERSEIFER, Tiago. Estado socioambiental e mínimo existencial (ecológico?): algumas aproximações. Estado socioambiental e direitos fundamentais. Porto Alegre: Livraria do Advogado, p. 11-38, 2010.

32 WOLKMER, Maria de Fátima Schumacher; DA SILVA PAULITSCH, Nicole. O Estado de Direito Socioambiental e a Governaça Ambiental: ponderações acerca da judicialização das políticas públicas ambientais e da atuação do poder judiciário. Novos Estudos Jurídicos, v. 18, n. 2, p. 256-268, 2013, p. 259-260.

33 KALIL, Ana Paula Maciel Costa; FERREIRA, Heline Sivini. A dimensão socioambiental do Estado de Direito. Veredas do Direito: Direito Ambiental e Desenvolvimento Sustentável, v. 14, n. 28 , p. 329-359, 2017, p. 346.

34 SARLET, Ingo Wolfgang; FENSTERSEIFER, Tiago. Estado socioambiental e mínimo existencial (ecológico?): algumas aproximações. Estado socioambiental e direitos fundamentais. Porto Alegre: Livraria do Advogado, p. 11-38, 2010, p. 22. 
HECKTHEUER, Pedro Abib; LOURENÇO, Bruna Borges Moreira. A efetivação dos direitos sociais como instrumento para o desenvolvimento na Constituição brasileira. Revista Eletrônica Direito e Política, Programa de Pós-Graduação Stricto Sensu em Ciência Jurídica da UNIVALI, Itajaí, v.14, n.2, $2^{\circ}$ quadrimestre de 2019. Disponível em: www.univali.br/direitoepolitica - ISSN 1980-7791

acontecerá se consciente da crise socioambiental, que será superada apenas então com uma ação conjunta entre Estado e sociedade.

Com isso, pode-se dizer que o conceito de desenvolvimento elaborado por Amartya Sen, para além do viés econômico, "certamente integra a concepção de desenvolvimento que a interpretação do texto constitucional permite construir" 35 .

E, para além disso, a Constituição Federal de 1988 comporta não só essa compreensão do desenvolvimento como liberdade, como vai além, por meio da ideia de um desenvolvimento socioambiental, ou seja, com vistas à sustentabilidade social e ambiental, um novo paradigma, que tem na liberdade política relevante mecanismo para sua efetivação.

É importante que se possa compreender como as Constituições passaram a dar efetividade aos novos elementos incorporados à ideia de desenvolvimento, motivo pelo qual se fará necessário, agora, compreender a positivação das liberdades instrumentais nos textos constitucionais dos Estados, e a importância dada por eles a esse tipo de direitos.

\section{A ESSENCIALIDADE dOS DIREITOS SOCIAIS E A PROIBIÇÃo dO RETROCESSO COMO UMA CONDIÇÃO AO DESENVOLVIMENTO}

Para que se possa esclarecer de que maneira os Estados nacionais passaram a positivar e viabilizar as liberdades instrumentais levantadas por Amartya Sen, fazse necessário analisar o movimento do constitucionalismo.

É por meio desse estudo que se poderá compreender a trajetória evolutiva dos direitos fundamentais, até o momento em que se passou a dar a eles, inclusos os direitos sociais, aplicabilidade direta e imediata, portanto, fazendo-se notar sua essencialidade ao pleno desenvolvimento de seus titulares.

35 FOLLONI, André. A complexidade ideológica, jurídica e política do desenvolvimento sustentável e a necessidade de compreensão interdisciplinar do problema. Revista de Direitos Humanos Fundamentais, Osasco, jan-jun/2014, ano 14, n.1, pp. 83. 
HECKTHEUER, Pedro Abib; LOURENÇO, Bruna Borges Moreira. A efetivação dos direitos sociais como instrumento para o desenvolvimento na Constituição brasileira. Revista Eletrônica Direito e Política, Programa de Pós-Graduação Stricto Sensu em Ciência Jurídica da UNIVALI, Itajaí, v.14, n.2, $2^{\circ}$ quadrimestre de 2019. Disponível em: www.univali.br/direitoepolitica - ISSN 1980-7791

O constitucionalismo é um movimento político que objetivou limitar e organizar o exercício do poder político, e isso se deu, em termos históricos, como um produto da Modernidade, oriunda do Iluminismo e das revoluções burguesas dos séculos XVII e XVIII, ocorridas na Inglaterra, Estados Unidos e França ${ }^{36}$. Ainda que se abordem teoricamente momentos anteriores a esse, nos denominados constitucionalismo antigo e medieval, com apontamentos históricos de limitações aos poderes políticos, é mesmo a partir do moderno que se importa aqui discutir, pois é com ele que se passa a limitar o poder do Estado em favor da liberdade individual, em oposição ao absolutismo ${ }^{37}$.

Esse modelo teórico de constitucionalismo concebeu o modelo liberal de constituição, fortemente inspirado pelas revoluções burguesas, assentando-o em três pilares essenciais, quais sejam: (1) a separação dos poderes, como forma de contenção do poder dos governantes; (2) a previsão de direitos individuais, concebidos como direitos negativos oponíveis ao Estado; e (3) a democracia representativa como meio de legitimação dos governos pelos governados ${ }^{38}$.

O constitucionalismo moderno passou a revelar a necessidade de registrar por escrito o documento fundamental do povo ${ }^{39}$, e assim seria considerado se houvesse a vinculação das constituições a esse conteúdo material supramencionado.

Essa ideia de constituição denominou-se idealismo constitucional, "por ser formulado em razão da própria matéria que a Constituição deve conter: aquela correspondente ao modelo liberal de Estado. O papel das constituições é organizar o exercício do poder político e limitá-10"40.

É importante destacar que os direitos do homem passaram a ter verdadeira relevância quando houve a radical inversão de perspectiva da relação

36 GRIMM, Dieter. Constitución y derechos fundamentales. Traducción de Raúl Sanz Burgos y José Luis Muños de Baena Simon. Madrid: Trotta, 2006, p. 27-28.

37 SOUZA NETO, Cláudio Pereira de; SARMENTO, Daniel. Direito constitucional: teoria, história e métodos de trabalho. 2a ed. Belo Horizonte: Fórum, 2014. p. 69-72.

38 SOUZA NETO, Cláudio Pereira de; SARMENTO, Daniel. Direito constitucional: teoria, história e métodos de trabalho. $2^{\mathrm{a}}$ ed. Belo Horizonte: Fórum, 2014. p. 74.

39 RAMOS, André Tavares. Curso de direito constitucional. 15a ed. São Paulo: Ed. Saraiva, 2017, p. 33.

40 SOUZA NETO, Cláudio Pereira de; SARMENTO, Daniel. Direito constitucional: teoria, história e métodos de trabalho. $2^{\mathrm{a}}$ ed. Belo Horizonte: Fórum, 2014. p. 184. 
HECKTHEUER, Pedro Abib; LOURENÇO, Bruna Borges Moreira. A efetivação dos direitos sociais como instrumento para o desenvolvimento na Constituição brasileira. Revista Eletrônica Direito e Política, Programa de Pós-Graduação Stricto Sensu em Ciência Jurídica da UNIVALI, Itajaí, v.14, n.2, $2^{\circ}$ quadrimestre de 2019. Disponível em: www.univali.br/direitoepolitica - ISSN 1980-7791

Estado/cidadão ou soberano/súdito, "relação que é encarada, cada vez mais, do ponto de vista dos direitos dos cidadãos não mais súditos, e não do ponto de vista dos direitos do soberano, em correspondência com a visão individualista da sociedade" ${ }^{\prime 1}$, característica do Estado moderno.

Como fora sublinhado, é no constitucionalismo moderno que as primeiras constituições escritas têm sua origem, daí em diante o movimento do constitucionalismo espraiou-se mundialmente. Passou-se a prever, em praticamente todos os Estados contemporâneos, formalmente, os seus documentos fundamentais, a Constituição, com exceções do caso da Inglaterra, dos Estados teocráticos, bem como no Direito muçulmano ${ }^{42}$.

As Constituições, desde as primeiras de caráter eminentemente liberal, passaram por constante processo de transformação pois - desde essa mudança na relação estado-cidadão, historicamente situada na concepção dos Estados modernos também os direitos fundamentais passaram por inúmeras transformações, seja com relação ao seu conteúdo, seja no que diz respeito à sua titularidade, eficácia e efetivação.

Não há como se falar em um processo evolutivo linear sobre a ideia de Estado, constituição e direitos humanos fundamentais, ainda assim, Karel Vasak trouxe a ideia de evolução dos direitos (humanos e fundamentais), de maneira a proporcionar uma análise das conquistas deste tipo de direitos sob uma

41 BOBBIO, Norberto. A era dos direitos. Rio de Janeiro: Campus, 1992, p. 4.

42 As primeiras constituições escritas que se tem registro são a Americana, de 1787, e a Francesa de 1891 (RAMOS, André Tavares. Curso de direito constitucional. 15a ed. São Paulo: Ed. Saraiva, 2017, p. 33-34). 
HECKTHEUER, Pedro Abib; LOURENÇO, Bruna Borges Moreira. A efetivação dos direitos sociais como instrumento para o desenvolvimento na Constituição brasileira. Revista Eletrônica Direito e Política, Programa de Pós-Graduação Stricto Sensu em Ciência Jurídica da UNIVALI, Itajaí, v.14, n.2, 20 quadrimestre de 2019. Disponível em: www.univali.br/direitoepolitica - ISSN 1980-7791

perspectiva geracional ${ }^{43,44}$, que foi aceita pelos estudiosos do tema, inclusive em âmbito nacional ${ }^{45,46}$, em que pese as críticas a esse modelo ${ }^{47}$.

A sua utilização deve-se à utilidade para que se possa melhor visualizar o conteúdo e as funções dos direitos fundamentais, sem olvidar que há entre os direitos fundamentais interdependência e integração, e que se trata apenas de um modo de apresentação da trajetória evolutiva. Com isso, abordar-se-ão, aqui, apenas as duas primeiras dimensões ${ }^{48}$ de direitos humanos fundamentais, ao tempo que se contextualizará estas com o constitucionalismo.

A primeira dimensão é característica do constitucionalismo francês e, portanto, do pensamento liberal-burguês do século XVIII, de traço individualista, típico do período em que se inverte a "tradicional relação entre Estado e indivíduo e se reconhece que o indivíduo tem, primeiro, direitos, e, depois, deveres perante o Estado, e que os direitos que o Estado tem em relação ao indivíduo se ordenam ao objetivo de melhor cuidar das necessidades dos cidadãos"49.

43 VASAK, Karel. Pour une troisième génération des droits de l'homme. Études et essais sur le droit internacional humanitaire et sur les príncipes de la Croix-Rouge em el honneur de Jean Pictet. Genève: La Haye, 1984.

44 PÉREZ LUÑO, Antonio Enrique. Las generaciones de derechos humanos. Revista da AGU, BrasíliaDF, ano XIII, n. 42, p. 39-74, out./dez. 2014.

45 SARLET, Ingo; MARINONI, Luiz Guilherme; MITIDIERO, Daniel. Curso de direito constitucional. 6a ed. Editora Saraiva, 2017.

46 BRANCO, Paulo Gustavo Gonet; COELHO, Inocêncio Mártires; MENDES, Gilmar Ferreira. Curso de direito constitucional. $12^{a}$ ed. São Paulo: Saraiva, 2017.

47 Várias críticas se dirigiram às "gerações" dos direitos fundamentais, por considerarem que o termo mais adequado deveria ser "dimensões", vez que "geração" implica uma ideia de alternância e substituição de uma por outra, quando na verdade deveria dar a conotação de complementariedade e cumulatividade, nesse sentido: BONAVIDES, Paulo. Curso de Direito Constitucional. 24a ed. São Paulo: Malheiros, 2009, p. 525; SARLET, Ingo; MARINONI, Luiz Guilherme; MITIDIERO, Daniel. Curso de direito constitucional. 6a ed. Editora Saraiva, 2017, p. 312 e ss.; BREGA FILHO, Vladimir. Direitos fundamentais na Constituição de 1988: conteúdo jurídico das expressões. Juarez de Oliveira, 2002, p 25 e ss.

48 Salienta-se que tratar-se-ão apenas das duas primeiras dimensões, pois é sobre os direitos previstos nestas duas dimensões que o presente projeto de pesquisa conducente a esta dissertação de mestrado delimitou a análise, ainda que seja de conhecimento a existência da terceira geração, bem como há, também, autores que defendam a existência de uma quarta e quinta geração de direitos humanos fundamentais, vem em: BONAVIDES, Paulo. Curso de Direito Constitucional. $16^{a}$ ed. São Paulo: Malheiros, 2005, p. 571; BONAVIDES, Paulo. Quinta geração de direitos fundamentais. Revista Direitos Fundamentais \& Justiça, ano 2, n.3, p. 82-ss., abr.-jun. 2008.

49 BRANCO, Paulo Gustavo Gonet; COELHO, Inocêncio Mártires; MENDES, Gilmar Ferreira. Curso de direito constitucional. $12^{a}$ ed. São Paulo: Saraiva, 2017, p. 134. 
HECKTHEUER, Pedro Abib; LOURENÇO, Bruna Borges Moreira. A efetivação dos direitos sociais como instrumento para o desenvolvimento na Constituição brasileira. Revista Eletrônica Direito e Política, Programa de Pós-Graduação Stricto Sensu em Ciência Jurídica da UNIVALI, Itajaí, v.14, n.2, $2^{\circ}$ quadrimestre de 2019. Disponível em: www.univali.br/direitoepolitica - ISSN 1980-7791

São os direitos conhecidos como "negativos", posto que se dirigem ao Estado como forma de abstenção, de não intervenção na seara individual, inseridos em uma perspectiva de direito de resistência e oposição perante o Estado ${ }^{50}$.

Podem-se arrolar, inicialmente, o direito à vida, à liberdade, à propriedade e à igualdade perante a lei, e de maneira subsequente passam a ser somados todos os meios de liberdades de expressão pública e os direitos de participação política ${ }^{51}$, ainda restritos ao direito de voto e à capacidade eleitoral passiva, mas já trazendo um alinhamento e correlação importante entre os direitos fundamentais e a democracia.

Também ficaram denominados de direitos civis e políticos, os de primeira geração ou negativos, que incluíam, além dos já nominados, algumas garantias processuais $^{52}$, que correspondem à fase inicial do constitucionalismo moderno e que perduram na ideia de Estado Democrático de Direito na atualidade ${ }^{53}$.

A segunda dimensão é oriunda do constitucionalismo social, fruto do grande impacto da industrialização e os consequentes problemas sociais e econômicos, fato que levou à compreensão de que a concepção formal de igualdade não proporcionava aos seus titulares o efetivo gozo desta garantia.

50 BONAVIDES, Paulo. Curso de Direito Constitucional. 24a ed. São Paulo: Malheiros, 2009 , p. 517

51 Deve-se salientar, aqui, que se está a referir do modelo de democracia elitista, abordado no primeiro capítulo desta dissertação.

52 Tais como o devido processo legal, habeas corpus, direito de petição, etc.

53 BONAVIDES, Paulo. Curso de Direito Constitucional. 24a ed. São Paulo: Malheiros, 2009 , p. 517. 
HECKTHEUER, Pedro Abib; LOURENÇO, Bruna Borges Moreira. A efetivação dos direitos sociais como instrumento para o desenvolvimento na Constituição brasileira. Revista Eletrônica Direito e Política, Programa de Pós-Graduação Stricto Sensu em Ciência Jurídica da UNIVALI, Itajaí, v.14, n.2, 20 quadrimestre de 2019. Disponível em: www.univali.br/direitoepolitica - ISSN 1980-7791

Essa realidade ganhava força pelas vertentes do pensamento ${ }^{54}$ que se insurgiam. Viabilizaram-se vários movimentos de reivindicação e reconhecimento de direitos que passariam a exigir do Estado uma posição ativa em busca da justiça social ${ }^{55,56}$.

A principal distinção com relação à primeira dimensão está no fato de nesta serem os seus direitos dirigidos a uma atuação ativa e positiva do Estado, ou seja, são endereçados aos poderes públicos para que eles proporcionem o bem-estar e justiça social ${ }^{57}$. Supera, portanto, aquela visão do constitucionalismo moderno, de apenas evitar a intervenção do Estado na esfera da liberdade individual.

São objetivos dos direitos desta dimensão assegurar aos indivíduos as prestações sociais por parte do Estado, tais como a assistência social, saúde, educação, trabalho, superando a perspectiva oitocentista de liberdade/igualdade formal, para uma liberdade/igualdade material, concreta. Esta dimensão engloba não apenas os direitos de cunho positivo, ainda que seja essa característica um marco distintivo desta fase, mas também as assim denominadas "liberdades sociais", como fazem exemplo a liberdade de sindicalização, o direito de greve e o reconhecimento de direitos fundamentais aos trabalhadores ${ }^{58}$.

Em que pese haver registro de constituições que previram tais tipos de direitos, de maneira isolada, ainda no século $X I^{59}$, é a partir do século seguinte, em especial nas constituições do período pós-guerra, que se passa a acolher nas

54 "No plano das ideias, contribuíram para esse desfecho diversas vertentes de pensamento, como o marxismo, o socialismo utópico e a doutrina social da Igreja Católica, que, embora divergindo profundamente quanto à solução, convergiam na crítica aos abusos a que conduzira o individualismo exacerbado do capitalismo selvagem, que prosperara sob a fachada do constitucionalismo liberal-burguês" (SOUZA NETO, Cláudio Pereira de; SARMENTO, Daniel. Direito constitucional: teoria, história e métodos de trabalho. $2^{\mathrm{a}}$ ed. Belo Horizonte: Fórum, 2014. p. 82).

${ }^{55}$ BRANCO, Paulo Gustavo Gonet; COELHO, Inocêncio Mártires; MENDES, Gilmar Ferreira. Curso de direito constitucional. $12^{\mathrm{a}}$ ed. São Paulo: Saraiva, 2017, p. 135.

56 SOUZA NETO, Cláudio Pereira de; SARMENTO, Daniel. Direito constitucional: teoria, história e métodos de trabalho. $2^{\mathrm{a}}$ ed. Belo Horizonte: Fórum, 2014. p. 82.

57 LAFER, Celso. A reconstrução dos direitos humanos: um diálogo com o pensamento de Hannah Arendt. Editora Companhia das Letras, 1988, p. 127.

58 "Tais como o direito a férias e ao repouso semanal remunerado, a garantia de um salário mínimo, a limitação da jornada de trabalho, apenas para citar alguns dos mais representativos" (SARLET, Ingo; MARINONI, Luiz Guilherme; MITIDIERO, Daniel. Curso de direito constitucional. 6a ed. Editora Saraiva, 2017, p. 315).

59 SARLET, Ingo; MARINONI, Luiz Guilherme; MITIDIERO, Daniel. Curso de direito constitucional. $6^{\mathrm{a}}$ ed. Editora Saraiva, 2017, p. 315. 
HECKTHEUER, Pedro Abib; LOURENÇO, Bruna Borges Moreira. A efetivação dos direitos sociais como instrumento para o desenvolvimento na Constituição brasileira. Revista Eletrônica Direito e Política, Programa de Pós-Graduação Stricto Sensu em Ciência Jurídica da UNIVALI, Itajaí, v.14, n.2, $2^{\circ}$ quadrimestre de 2019. Disponível em: www.univali.br/direitoepolitica - ISSN 1980-7791

Constituições os valores do Estado Social. As Constituições Zapatista (1917), no México, e a de Weimer (1919), na Alemanha, foram as que deram o pontapé inicial na previsão destes direitos nos textos constitucionais, inaugurando a ideia de constitucionalismo social ${ }^{60}$.

A maior parte das constituições da segunda metade do século passado seguiu, com maior ou menor sucesso, a fórmula do Estado Social. No entanto, é importante se compreender que ao longo desse período de afirmação do denominado Estado Social, o reconhecimento de direitos a prestações sociais não se deu de maneira linear e tampouco homogênea, assim como não foi em todos os Estados constitucionais enquadrados como na ideia de Estado Social, em que se reconheceram no plano constitucional e como direitos subjetivos, ainda que fossem previstos, em vários casos, na legislação infraconstitucional ${ }^{61}$.

Compreendidos, ainda que de maneira sucinta, a evolução dos direitos fundamentais - em especial as duas dimensões de direitos humanos fundamentais que são essenciais ao enfrentamento do problema desta pesquisa , faz-se necessário enfatizar que ainda que o surgimento destes direitos datem de muito tempo, as suas aplicabilidades e efetividades, em especial os de segunda dimensão, não eram diretas e imediatas à seus titulares, por uma série de fatores que não se objetiva aqui explorar.

O fato é que, em função disso, o direito constitucional passou por um conjunto de mudanças e transformações, a partir da Segunda Guerra Mundial e da redemocratização, nos países romano-germânicos ${ }^{62}$, que o modificaram, consideravelmente. Essa mudança se deu, principalmente, no que diz respeito ao modo como o direito constitucional é pensado e praticado, por meio de uma

60 SOUZA NETO, Cláudio Pereira de; SARMENTO, Daniel. Direito constitucional: teoria, história e métodos de trabalho. $2^{\mathrm{a}}$ ed. Belo Horizonte: Fórum, 2014. p. 84.

61 SARLET, Ingo; MARINONI, Luiz Guilherme; MITIDIERO, Daniel. Curso de direito constitucional. 6 a ed. Editora Saraiva, 2017, p. 315.

62 Sobre essas mudanças e transformações, que são relacionadas diretamente ao que a literatura denomina de neoconstitucionalismo, pode-se aprofundar em: BARROSO, Luís Roberto. Curso de direito constitucional contemporâneo: os conceitos fundamentais e a construção do novo modelo. 6a ed. São Paulo: Saraiva, 2017, p. 529 e ss.; SOUZA NETO, Cláudio Pereira de; SARMENTO, Daniel. Direito constitucional: teoria, história e métodos de trabalho. $2^{a}$ ed. Belo Horizonte: Fórum, 2014. p. 199 e ss. 
HECKTHEUER, Pedro Abib; LOURENÇO, Bruna Borges Moreira. A efetivação dos direitos sociais como instrumento para o desenvolvimento na Constituição brasileira. Revista Eletrônica Direito e Política, Programa de Pós-Graduação Stricto Sensu em Ciência Jurídica da UNIVALI, Itajaí, v.14, n.2, $2^{\circ}$ quadrimestre de 2019. Disponível em: www.univali.br/direitoepolitica - ISSN 1980-7791

superação de paradigmas que mobilizaram a "doutrina e a jurisprudência nesse período, criando uma nova percepção da Constituição e de seu papel na interpretação jurídica em geral"63.

Dessa forma, é somente com as Constituições do segundo pós-guerra que as cartas deixam de ser procedimentais - apenas definindo regras do jogo político, em que quase tudo era deixado para as decisões das maiorias legislativas - e passam a ter um importante teor axiológico, debruçando-se nas questões até então olvidadas pelos textos constitucionais, aproximando o Direito da Moral ${ }^{64}$, modelo teórico que ficou denominado de neoconstitucionalismo ${ }^{65}$.

Estas teorias neoconstitucionalistas buscaram construir novas perspectivas teóricas que proporcionassem, entre outras coisas, dar aplicabilidade direta e imediata aos direitos fundamentais, o que se possibilitou com a força normativa dada à Constituição ${ }^{66}$ e seus princípios.

Dá-se, portanto, concretude e aplicabilidade aos direitos humanos fundamentais, de primeira e segunda dimensão, por meio da valorização da razão prática no âmbito jurídico, em superação ao ideal positivista. Supera-se a ideia de compreender como racional apenas aquilo que podia ser comprovado de forma experimental, ou deduzido de premissas gerais, de acordo com a lógica formal, passando a também compreender como racional a argumentação empregada na resolução de questões práticas, nas quais o Direito, necessariamente, é compelido a equacionar ${ }^{67}$.

A Constituição Brasileira de 1988 consagrou, expressamente, os direitos de primeira e segunda dimensões, na forma de regras e princípios, prevendo,

63 BARROSO, Luís Roberto. Curso de direito constitucional contemporâneo: os conceitos fundamentais e a construção do novo modelo. 6a ed. São Paulo: Saraiva, 2017, p. 529-530.

64 SOUZA NETO, Cláudio Pereira de; SARMENTO, Daniel. Direito constitucional: teoria, história e métodos de trabalho. 2a ed. Belo Horizonte: Fórum, 2014. p. 202.

65 Sobre o neoconstitucionalismo, recomenda-se a leitura de: CARBONELL, Miguel. Teoría del neoconstitucionalismo: ensayos escogidos. Madrid: Trotta, 2007; CARBONELL, Miguel (org.). Neoconstitucionalismo. Madrid: Trotta, 2003.

66 HESSE, Konrad. A força normativa da Constituição: Die normative Kraft der Verfassung. Tradução Gilmar Ferreira Mendes. Porto Alegre: Sérgio Antonio Fabris Editor, 1991.

67 SOUZA NETO, Cláudio Pereira de; SARMENTO, Daniel. Direito constitucional: teoria, história e métodos de trabalho. 2a ed. Belo Horizonte: Fórum, 2014. p. 203. 
HECKTHEUER, Pedro Abib; LOURENÇO, Bruna Borges Moreira. A efetivação dos direitos sociais como instrumento para o desenvolvimento na Constituição brasileira. Revista Eletrônica Direito e Política, Programa de Pós-Graduação Stricto Sensu em Ciência Jurídica da UNIVALI, Itajaí, v.14, n.2, $2^{\circ}$ quadrimestre de 2019. Disponível em: www.univali.br/direitoepolitica - ISSN 1980-7791

também, diversos deveres estatais correlatos a esses direitos. Isso trouxe importantes consequências para o sistema de direitos fundamentais, vez que deslegitima o discurso de uma possível indeterminação constitucional do conteúdo desse tipo de direitos, o que Ihes garante alicerce constitucional.

Souza Neto acentua a importância dos direitos fundamentais de segunda geração, ao considerar que seria moralmente inaceitável, em países subdesenvolvidos ou em desenvolvimento, que possuem como características essenciais a injustiça social e a desigualdade material, pôr fim à implementação dos direitos previstos pelo constitucionalismo social, pois considera que deve haver um mecanismo "que imponha, por cima das deliberações da política ordinária, o dever do Estado e da sociedade de reduzirem a miséria e a desigualdade, e possibilitarem a fruição efetiva de direitos fundamentais pelos integrantes dos setores mais vulneráveis da sociedade" 68 .

A esse respeito, autores trabalham teoricamente o denominado princípio da proibição do retrocesso social, dada a importância deste tipo de direitos ao desenvolvimento das pessoas. É de se destacar que não há previsão expressa deste princípio nas constituições, porém, ainda que não seja um posicionamento unânime, já serviu para decisões de Tribunais Constitucionais.

O princípio de vedação do retrocesso social seria uma "norma jusfundamental adscrita, de natureza principal, que proíbe ao legislador a supressão ou alteração das normas infraconstitucionais que densificam normas constitucionais de direitos sociais de modo a violar a sua eficácia"69. Portanto, as leis que dão maior densidade aos direitos fundamentais, ou seja, que ampliam sua eficácia e Ihes dão maior efetividade, não poderiam ser restringidas ou revogadas de maneira a configurar um retrocesso, pois violaria cláusula pétrea da constituição federal, e representaria uma inconstitucionalidade.

68 SOUZA NETO, Cláudio Pereira de; SARMENTO, Daniel. Direito constitucional: teoria, história e métodos de trabalho. $2^{\mathrm{a}}$ ed. Belo Horizonte: Fórum, 2014. p. 86.

69 PINTO E NETTO, Luísa Cristina. O princípio de proibição de retrocesso social. Porto Alegre: Livraria do Advogado, 2010, p. 227. 
HECKTHEUER, Pedro Abib; LOURENÇO, Bruna Borges Moreira. A efetivação dos direitos sociais como instrumento para o desenvolvimento na Constituição brasileira. Revista Eletrônica Direito e Política, Programa de Pós-Graduação Stricto Sensu em Ciência Jurídica da UNIVALI, Itajaí, v.14, n.2, $2^{\circ}$ quadrimestre de 2019. Disponível em: www.univali.br/direitoepolitica - ISSN 1980-7791

Canotilho compreende que "os direitos sociais e económicos" obtém "um determinado grau de realização (e) passam a constituir, simultaneamente, uma garantia institucional e um direito subjetivo"70, de maneira que o princípio encontraria justificação, entre outras, na proteção da confiança dos cidadãos ${ }^{71}$.

No Brasil, foi a Constituição Federal de 1988 que permitiu o debate que aqui se trata sobre a proibição do retrocesso, em virtude dos fundamentos que anteriormente já se discutiram, pois é nela que se prescreveram diversas normas, ampliando o rol de direitos fundamentais de cunho social e econômico. Essas que eram compreendidas como normas de eficácia limitada ${ }^{72}$, pois exigem uma interlocução por meio de uma atividade integradora do legislador infraconstitucional como forma de dar conteúdo e concretização a essas normas, por meio de serviços ou políticas públicas.

Ainda que não haja expressa previsão, o princípio da vedação do retrocesso se fundamenta: (1) na supremacia constitucional, na análise desta enquanto um conjunto normativo superior na ordem jurídica e pela exigência de concretização dos preceitos constitucionais; (2) para dar cumprimento ao postulado da máxima eficácia das normas de direitos fundamentais; e (3) nos princípios estruturantes do Estado Constitucional ${ }^{73}$, quais sejam, o democrático ${ }^{74}$, da socialidade $^{75}$ e da juridicidade $^{76}$.

Dessa forma, extrai-se da constituição brasileira, por meio de uma análise sistêmica, uma imposição ao legislador de legislar para dar máxima eficácia aos

70 CANOTILHO, J. J. Gomes. Direito Constitucional e teoria da constituição. 5. ed. Coimbra: Almedina, 2003, p. 338-339.

71 MIRANDA, Jorge. Manual de direito constitucional. Coimbra: Coimbra, t. IV., 1988, p. 397.

72 DA SILVA, José Afonso. Aplicabilidade das normas constitucionais. $8^{a}$ ed. São Paulo: Saraiva, 2012.

73 PINTO E NETTO, Luísa Cristina. O princípio de proibição de retrocesso social. Porto Alegre: Livraria do Advogado, 2010, p. 227-228.

74 "Reclama a efetivação não só dos direitos de liberdade, mas também dos direitos sociais, como condição de sua eficácia" (PINTO E NETTO, Luísa Cristina. O princípio de proibição de retrocesso social. 2010, p. 228).

75 "Impõe a vinculação jurídica do Estado à criação de condições materiais de existência digna para os indivíduos" (PINTO E NETTO, Luísa Cristina. O princípio de proibição de retrocesso social. 2010, p. 228).

76 "Determina que as atuações estatais se pautem por critérios jurídicos pré-estabelecidos e postula uma certa estabilidade da ordem jurídica" (PINTO E NETTO, Luísa Cristina. O princípio de proibição de retrocesso social. 2010, p. 228). 
HECKTHEUER, Pedro Abib; LOURENÇO, Bruna Borges Moreira. A efetivação dos direitos sociais como instrumento para o desenvolvimento na Constituição brasileira. Revista Eletrônica Direito e Política, Programa de Pós-Graduação Stricto Sensu em Ciência Jurídica da UNIVALI, Itajaí, v.14, n.2, $2^{\circ}$ quadrimestre de 2019. Disponível em: www.univali.br/direitoepolitica - ISSN 1980-7791

direitos sociais e, por outro lado, uma vedação ao legislador de legislar contrariamente à eficácia dos direitos sociais, sendo esta previsão de forma definitiva como forma de concretizar o núcleo essencial dos direitos sociais ${ }^{77,78}$.

Dentro desta teorização da proibição do retrocesso, não se está a impor uma proibição absoluta a ponto de não permitir a compatibilização com os demais elementos do sistema jurídico, mas apenas assim poderá acontecer, se o retrocesso não atingir o núcleo essencial do direito social e for racionalmente fundado, apenas cedendo diante de ponderação proporcional ${ }^{79}$.

Os direitos fundamentais e sociais são, portanto, a fórmula constitucional de positivação das liberdades instrumentais, tendo sido demonstrado, por meio do processo evolutivo dos direitos fundamentais, a busca pelo alcance e pela efetivação e aplicabilidade destes direitos.

Isso porque são eles os instrumentos de realização do desenvolvimento das pessoas, porquanto que exigem uma atuação - negativa ou positiva - do Estado no sentido de proporcionar aos seus titulares as condições de usufruírem, plenamente, de suas liberdades instrumentais. Tamanha é a importância deste tipo de direitos para o desenvolvimento, que o princípio da vedação do retrocesso impede que a legislação infraconstitucional possa diminuir a densidade já garantida, devendo, sempre, haver o máximo cumprimento e efetividade desse tipo de direitos.

\section{CONSIDERAÇÕES FINAIS}

Trabalhou-se na presente pesquisa uma perspectiva de Desenvolvimento como Liberdade, teorizado por Amartya Sen, que tornou o conceito de desenvolvimento mais dinâmico, como um processo de expansão das liberdades reais que as

\footnotetext{
77 BARROSO, Luís Roberto. O direito constitucional e a efetividade de suas normas. 5. ed. Rio de Janeiro: Renovar, 2001, p. 158.

78 DERBLI, Felipe. Proibição de retrocesso social: uma proposta de sistematização à luz da Constituição de 1988. In: BARROSO, Luís Roberto (Org.). A reconstrução democrática do direito público no Brasil. Rio de Janeiro: Renovar, p. 433-495, 2007, p. 434.

79 PINTO E NETTO, Luísa Cristina. O princípio de proibição de retrocesso social. Porto Alegre: Livraria do Advogado, 2010, p. 232-233.
} 
HECKTHEUER, Pedro Abib; LOURENÇO, Bruna Borges Moreira. A efetivação dos direitos sociais como instrumento para o desenvolvimento na Constituição brasileira. Revista Eletrônica Direito e Política, Programa de Pós-Graduação Stricto Sensu em Ciência Jurídica da UNIVALI, Itajaí, v.14, n.2, $2^{\circ}$ quadrimestre de 2019. Disponível em: www.univali.br/direitoepolitica - ISSN 1980-7791

pessoas podem disfrutar, sendo um rompimento com o viés economicista das primeiras décadas do período que sucedeu a Segunda Guerra Mundial.

Tendo sido identificado que a discussão sobre esse fenômeno foi inaugurada, em termos constitucionais, de maneira efetiva, apenas na Constituição Federal de 1988, compreende-se que o conceito elaborado por Amartya Sen, para além do viés econômico, integra a concepção de desenvolvimento que a interpretação do texto constitucional permite construir. Mais do que isso, a Constituição incorpora a concepção do desenvolvimento o aspecto socioambiental.

Posteriormente, passou-se a verificar de que maneira as constituições passaram a positivar as ditas liberdades instrumentais, exigindo que, para isso, fosse compreendido o processo evolutivo dos direitos humanos fundamentais, dentre os quais devem ser inseridos, também, os direitos sociais, pois é por meio destes que se concretizam as liberdades instrumentais ao desenvolvimento dos cidadãos nos Estados nacionais.

São eles os instrumentos de realização do desenvolvimento das pessoas, porquanto que exigem uma atuação - negativa ou positiva - do Estado no sentido de proporcionar aos seus titulares as condições de usufruírem, plenamente, de suas liberdades instrumentais.

Foi, portanto, o problema da pesquisa respondido, a hipótese confirmada e o objetivo alcançado, pois, ficou evidente a importância dos direitos sociais para o desenvolvimento quando se analisa o princípio da vedação do retrocesso, que impede que a legislação infraconstitucional possa diminuir a densidade a eles já garantida, devendo, sempre, haver o máximo cumprimento e efetividade desse tipo de direitos, sob pena de descumprimento do mandamento constitucional.

\section{REFERÊNCIAS DAS FONTES CITADAS}

BARROSO, Luís Roberto. Curso de direito constitucional contemporâneo: os conceitos fundamentais e a construção do novo modelo. $6^{a}$ ed. São Paulo: Saraiva, 2017. 
HECKTHEUER, Pedro Abib; LOURENÇO, Bruna Borges Moreira. A efetivação dos direitos sociais como instrumento para o desenvolvimento na Constituição brasileira. Revista Eletrônica Direito e Política, Programa de Pós-Graduação Stricto Sensu em Ciência Jurídica da UNIVALI, Itajaí, v.14, n.2, $2^{\circ}$ quadrimestre de 2019. Disponível em: www.univali.br/direitoepolitica - ISSN 1980-7791

BARROSO, Luís Roberto. O direito constitucional e a efetividade de suas normas. 5. ed. Rio de Janeiro: Renovar, 2001.

BOBBIO, Norberto. A era dos direitos. Rio de Janeiro: Campus, 1992.

BONAVIDES, Paulo. Curso de Direito Constitucional. $16^{a}$ ed. São Paulo: Malheiros, 2005.

BONAVIDES, Paulo. Quinta geração de direitos fundamentais. Revista Direitos Fundamentais \& Justiça, ano 2, n.3, p. 82-ss., abr.-jun. 2008.

BONAVIDES, Paulo. Curso de Direito Constitucional. 24a ed. São Paulo: Malheiros, 2009.

BRANCO, Paulo Gustavo Gonet; COELHO, Inocêncio Mártires; MENDES, Gilmar Ferreira. Curso de direito constitucional. 12a ed. São Paulo: Saraiva, 2017.

BRASIL. Constituição da República Federativa do Brasil. Brasília: Senado Federal, 1988.

BREGA FILHO, Vladimir. Direitos fundamentais na Constituição de 1988: conteúdo jurídico das expressões. Juarez de Oliveira, 2002.

BRESSER-PEREIRA, Luiz Carlos. Desenvolvimento e Crise no Brasil. São Paulo: Brasiliense, 1977.

CANOTILHO, J. J. Gomes. Direito Constitucional e teoria da constituição. 5. ed. Coimbra: Almedina, 2003.

CARBONELL, Miguel. Teoría del neoconstitucionalismo: ensayos escogidos. Madrid: Trotta, 2007.

CARBONELL, Miguel (org.). Neoconstitucionalismo. Madrid: Trotta, 2003.

CHUÍ, Marilena. O que é a ideologia. 2. ed. São Paulo, Brasiliense, 1981, p. 81).

DA SILVA, José Afonso. Aplicabilidade das normas constitucionais. $8^{a}$ ed. São Paulo: Saraiva, 2012.

DERBLI, Felipe. Proibição de retrocesso social: uma proposta de sistematização à luz da Constituição de 1988.

BARROSO, Luís Roberto (Org.). A reconstrução democrática do direito público no Brasil. Rio de Janeiro: Renovar, p. 433-495, 2007, p. 434.

FACHIN, Melina Girardi. Direito fundamental ao desenvolvimento: uma possível ressignificação entre a Constituição Brasileira e o Sistema Internacional de Proteção dos Direitos Humanos. PIOVESAN, Flávia; SOARES, Inês Virgínia Prado (Coords.). Direito ao desenvolvimento. Belo Horizonte: Fórum, p. 179-198, 2010, p. 180-193. 
HECKTHEUER, Pedro Abib; LOURENÇO, Bruna Borges Moreira. A efetivação dos direitos sociais como instrumento para o desenvolvimento na Constituição brasileira. Revista Eletrônica Direito e Política, Programa de Pós-Graduação Stricto Sensu em Ciência Jurídica da UNIVALI, Itajaí, v.14, n.2, $2^{\circ}$ quadrimestre de 2019. Disponível em: www.univali.br/direitoepolitica - ISSN 1980-7791

FOLLONI, André. A complexidade ideológica, jurídica e política do desenvolvimento sustentável e a necessidade de compreensão interdisciplinar do problema. Revista de Direitos Humanos Fundamentais, Osasco, jan-jun/2014, ano 14, n.1, pp. 83.

FURTADO, Celso. Desenvolvimento e subdesenvolvimento. Rio de Janeiro: Contraponto/Centro Internacional Celso Furtado, 2009.

GRIMM, Dieter. Constitución y derechos fundamentales. Traducción de Raúl Sanz Burgos y José Luis Muños de Baena Simon. Madrid: Trotta, 2006.

HACHEM, Daniel Wunder. A noção constitucional de desenvolvimento para além do viés econômico: reflexos sobre algumas tendências do Direito Público brasileiro. A\&C Revista de Direito Administrativo \& Constitucional, Belo Horizonte, ano 13, n. 53, p. 133-168, jul./set. 2013.

HESSE, Konrad. A força normativa da Constituição: Die normative Kraft der Verfassung. Tradução Gilmar Ferreira Mendes. Porto Alegre: Sérgio Antonio Fabris Editor, 1991.

JÚNIOR, José Celso Cardoso; SIQUEIRA, Carlos Henrique Romão. Complexidade \& desenvolvimento: abordagem metodológica e panorama da discussão propagada pelo Ipea entre 2008 e 2010. Economia e Sociedade, v. 21, n. 4.

KALIL, Ana Paula Maciel Costa; FERREIRA, Heline Sivini. A dimensão socioambiental do Estado de Direito. Veredas do Direito: Direito Ambiental e Desenvolvimento Sustentável, v. 14, n. 28, p. 329-359, 2017.

LAFER, Celso. A reconstrução dos direitos humanos: um diálogo com o pensamento de Hannah Arendt. Editora Companhia das Letras, 1988.

MARÉS, Carlos Frederico. Introdução ao direito socioambiental. In: LIMA, André (Org.). O direito para o Brasil socioambiental. São Paulo: Instituto Socioambiental; Porto Alegre: Sérgio Antônio Fabris, 2002.

MIRANDA, Jorge. Manual de direito constitucional. Coimbra: Coimbra, t. IV., 1988.

MOLINARO, Carlos Alerto. Racionalidade ecológica e estado socioambiental e democrático de direito. 2006. 200 f. Dissertação (Mestrado em Direito) Faculdade de Direito, Pontifícia Universidade Católica do Rio Grande do Sul, Porto Alegre, 2006.

PÉREZ LUÑO, Antonio Enrique. Las generaciones de derechos humanos. Revista da AGU, Brasília-DF, ano XIII, n. 42, p. 39-74, out./dez. 2014.

PINTO E NETTO, Luísa Cristina. O princípio de proibição de retrocesso social. Porto Alegre: Livraria do Advogado, 2010. 
HECKTHEUER, Pedro Abib; LOURENÇO, Bruna Borges Moreira. A efetivação dos direitos sociais como instrumento para o desenvolvimento na Constituição brasileira. Revista Eletrônica Direito e Política, Programa de Pós-Graduação Stricto Sensu em Ciência Jurídica da UNIVALI, Itajaí, v.14, n.2, $2^{\circ}$ quadrimestre de 2019. Disponível em: www.univali.br/direitoepolitica - ISSN 1980-7791

PINTO E NETTO, Luísa Cristina. O princípio de proibição de retrocesso social. Porto Alegre: Livraria do Advogado, 2010.

PIRES, Breiller. Brasil despenca 19 posições em ranking de desigualdade social da ONU. EI País, São Paulo, 21 de Março de 2017. Disponível em: https://brasil.elpais.com/brasil/2017/03/21/politica/1490112229 963711.html.

Acessado em: 09/02/2018.

RAMOS, André Tavares. Curso de direito constitucional. 15a ed. São Paulo: Ed. Saraiva, 2017.

SANTILLI, Juliana. Socioambientalismo e novos direitos: proteção jurídica à diversidade biológica e cultural. Editora Peirópolis LTDA, 2005.

SARLET, Ingo Wolfgang; FENSTERSEIFER, Tiago. Estado socioambiental e mínimo existencial (ecológico?): algumas aproximações. Estado socioambiental e direitos fundamentais. Porto Alegre: Livraria do Advogado, p. 11$38,2010$.

SARLET, Ingo; MARINONI, Luiz Guilherme; MITIDIERO, Daniel. Curso de direito constitucional. 6a ed. Editora Saraiva, 2017.

SEN, Amartya. Desenvolvimento como Liberdade. São Paulo: Companhia das Letras, 2000.

SOUZA NETO, Cláudio Pereira de; SARMENTO, Daniel. Direito constitucional: teoria, história e métodos de trabalho. $2^{a}$ ed. Belo Horizonte: Fórum, 2014.

VASAK, Karel. Pour une troisième génération des droits de I'homme. Études et essais sur le droit internacional humanitaire et sur les príncipes de la CroixRouge em el honneur de Jean Pictet. Genève: La Haye, 1984.

WOLKMER, Maria de Fátima Schumacher; DA SILVA PAULITSCH, Nicole. O Estado de Direito Socioambiental e a Governaça Ambiental: ponderações acerca da judicialização das políticas públicas ambientais e da atuação do poder judiciário. Novos Estudos Jurídicos, v. 18, n. 2, p. 256-268, 2013, p. 260.

RECEBIDO EM: 06/05/2019

APROVADO EM: 23/07/2019 